\title{
Ultrastructural Morphology and Cytochemistry of Iron-Deficient Polymorphonuclear Leukocytes ${ }^{1}$
}

\author{
R. T. Parmley, 2,3 J. C. Barton, 4 C. Fittschen, ${ }^{5}$ and L. A. Boxer 6 \\ ${ }^{2}$ Department of Pediatrics and Pathology, The University of Texas Health Science Center at San \\ Antonio; ${ }^{4}$ Department of Medicine and ${ }^{5}$ Comparative Medicine, University of Alabama at \\ Birmingham; the 4,5 Veterans Administration Hospital, Birmingham, Alabama; and 'Department of \\ Pediatrics, University of Michigan, Ann Arbor, Michigan
}

Received October 8, 1985, and in revised form October 28, 1985

\begin{abstract}
Previous studies have documented decreased activities of certain enzymes and altered function in polymorphonuclear leukocytes (PMN) during iron deficiency. The present study was undertaken to determine if the enzymatic abnormalities could be correlated with morphologic or quantitative change in PMN granules. Ultrastructural examination of primary and secondary granules and assessment of the secondary granule components alkaline phosphatase and vicinal glycol-containing glycoconjugates was performed in rabbit bone marrow, peripheral blood, and peritoneal heterophils. In addition, biochemical quantifications of the secondary granule component alkaline phosphatase and the primary granule marker $\beta$-glucuronidase were performed. The results confirmed that a marked, significant decrease in alkaline phosphatase occurs in iron-deficient animals; however, no biochemical decrease in $\beta$-glucuronidase activity was observed. Ultrastructurally, PMN secondary granules of iron-deficient rabbits tended to be more numerous than in controls when examined with morphometric and glycoconjugate staining methods, but lacked staining in alkaline phosphatase preparations. These results demonstrate that iron-deficient rabbits produce normal to increased quantities of primary and secondary granules, despite a uniform deficiency of alkaline phosphatase, a secondary granule marker. 1986 Academic Press. Inc.
\end{abstract}

\section{INTRODUCTION}

The bactericidal capacity of PMN is decreased in iron deficiency (Chandra, 1973; Yetgin et al., 1979). Hexose monophosphate shunt activation and reduction of nitroblue tetrazolium are decreased in iron-deficient rabbits and humans (Celada et al., 1979; Yetgin et al., 1979). Similarly, myeloperoxidase-mediated iodination is decreased in PMN from iron-deficient humans (Prasad, 1979). Myeloperoxidase activity has been reported to be normal (Yetgin $e t$ al., 1979) or decreased (Mackler et al., 1984; Sinha and Swarup-Mitra, 1981) in iron deficiency. A decrease in leukocyte alkaline phosphatase (LAP) has been demonstrated in irondeficient rabbits (Celada et al., 1979). In some humans with iron deficiency, a decrease in PMN and serum lactoferrin has been reported (deVet and Ten Hoopen, 1978). The present study was undertaken to determine if morphological or quantitative decreases in PMN granules could be correlated with a decrease in granule constituents during iron deficiency.

\section{MATERIALS AND METHODS}

Preparation of animals. The principles of laboratory animal care as promulgated by the National Research Council were observed. New Zealand White rabbits (Myrtle's Rabbitry, Thompson Station, Tenn.) were designated randomly as either control animals $(n=4)$ or those to be made iron-deficient $(\mathrm{FeD}, n=5)$.

1 Supported in part by grants from the National Institutes of Health IK AM 000752, A1220065, HL31963, and The Veterans Administration.

${ }^{3}$ To whom requests for reprints should be addressed at Department of Pediatrics and Pathology, The University of Texas Health Science Center at San Antonio, 7703 Floyd Curl Drive, San Antonio, Texas 78284 . 
Throughout the experiments, control rabbits were fed a purified agar gel diet (Hunt and Harrington, 1974) and FeD rabbits were given a similar diet from which $\mathrm{FePO}_{4}$ was omitted. These diets thus contained approximately 592 and 3 $\mathrm{mg} \mathrm{Fe} / \mathrm{kg}$ dry wt, respectively; these calculated results were confirmed by analysis of diet samples using atomic absorption spectroscopy (Perkin-Elmer Model 303, Perkin-Elmer Corp., Instrument Div., Norwalk, Conn.). Diets and demineralized deionized water were given ad libitum. All rabbits were individually housed in galvanized steel cages in a room with automatically controlled temperature $\left(22^{\circ} \mathrm{C}\right)$ and lighting $(12 \mathrm{hr})$. FeD rabbits were bled by cardiac puncture $(78.4$ $\pm 26.6 \mathrm{ml} / \mathrm{kg}$ of original weight) at intervals thereafter to produce iron deficiency. Neither control nor FeD rabbits were bled within 7 days of the termination of the experiment.

Marrow and blood samples. Initially, $10 \mathrm{ml}$ of blood was removed by cardiac puncture from control $(n=4)$ and $\mathrm{FeD}(n=5)$ animals for hematologic, light microscopic, and chemical determinations. Microhematocrits were determined by a capillary tube method. Serum iron concentrations and total serum ironbinding capacities were quantified using an automated bathophenanthroline technique (ACA II: DuPont Automated Clinical Analyzer, DuPont Systems Automatic Clinical Analysis Division, Atlanta, Ga.). Peripheral blood LAP was quantified using a standard method of staining and scoring (Okun and Tanaka, 1978). At the termination of the experiment, similar studies were repeated and, in addition, a heparinized blood sample $(5 \mathrm{cc})$ taken by cardiac puncture was obtained for ultrastructural evaluation as described below. The rabbits were then killed by cervical dislocation and a sample of femoral marrow was obtained for ultrastructural studies.

Peritoneal wash samples. An additional set of control $(n=2)$ and FeD $(n=4)$ rabbits were similarly prepared for the obtainment of peritoneal wash heterophils for ultrastructural and biochemical studies. Iron deficiency was documented using microhematocrit, serum iron concentration, and total serum iron-binding capacity. After light sedation of rabbits with an intramuscular injection of Rompum $(2 \mathrm{mg} / \mathrm{kg})$ and Ketamine $(20 \mathrm{mg} / \mathrm{kg})$, the peritoneal cavity was injected with $150-200 \mathrm{ml}$ of $0.9 \%$ saline containing $0.1 \%$ oyster glycogen (Sigma Chemical Co., St. Louis, Mo.). After $24 \mathrm{hr}$, the rabbits were heavily sedated with Rompum $(10 \mathrm{mg} / \mathrm{kg})$ and Ketamine $(50 \mathrm{mg} / \mathrm{kg})$ and the peritoneal cavity was injected with $200 \mathrm{ml}$ of $0.9 \%$ saline with $1 \mathrm{unit} / \mathrm{ml}$ of heparin. A surgical incision was made, a catheter was inserted into the peritoneum, and the peritoneal fluid was collected by gravity. The cells were collected by centrifugation $(1500 \mathrm{~g}$ for $10 \mathrm{~min})$ at $4^{\circ} \mathrm{C}$. Some cells were then processed for electron microscopy as described below. Other samples were resuspended for $30 \mathrm{sec}$ in a lysing solution consisting of 0.15 $\mathrm{mM} \mathrm{NH}_{4} \mathrm{Cl}, 0.01 \mathrm{~m} M \mathrm{NaHCO}_{3}$, and $1.0 \mathrm{~m} M$ ethylenediaminetetraacetic acid. The suspensions were centrifuged, and the cells were collected and rinsed twice in phosphate-buffered saline (PBS). The cells were divided into 1-ml aliquots in PBS containing $10^{7}-10^{8}$ cells each and frozen at $-20^{\circ} \mathrm{C}$. The samples were then processed for biochemical determination of $\beta$-glucuronidase (Michell et al., 1970) and alkaline phosphatase (Bretz and Baggiolini, 1974).

Electron microscopy. Blood samples were collected in heparinized syringes and centrifuged in 1-ml glass tubes at $1500 \mathrm{~g}$ for $3 \mathrm{~min}$. The plasma was removed and the buffy coat overlaid with $3 \%$ glutaraldehyde $/ 0.1 M$ cacodylate buffer, $\mathrm{pH}$ 7.35 , at $4-10^{\circ} \mathrm{C}$. After $10 \mathrm{~min}$, the buffy coat was removed and minced in fixative 
with a razor blade and allowed to fix an additional $50 \mathrm{~min}$. Femoral marrow tissue was either directly minced in fixative and allowed to fix for $1 \mathrm{hr}$, or resuspended in PBS, centrifuged, and resuspended in fixative for $1 \mathrm{hr}$. Peritoneal wash cell pellets were fixed as a tissue pellet and minced in the fixative or resuspended in the fixative. All samples were then rinsed in $0.1 \mathrm{M}$ cacodylatc, $7 \mathrm{~g} / \mathrm{dl}$ sucrose, $\mathrm{pH}$ 7.35 .

In addition to routine morphologic studies, specimens were processed for alkaline phosphatase (Mayahara et al., 1967); a secondary granule constituent (Wetzel et al., 1967b); peroxidase (Graham and Karnovsky, 1966); a primary granule marker (Dunn et al., 1968); acid phosphatase (Barka and Anderson, 1967); a primary granule constituent (Wetzel et al., 1967b); and vicinal glycol staining after amylase digestion for localization of glycoprotein-rich secondary granules (Fittschen et al., 1983). All specimens except those processed for vicinal glycol staining were postfixed in $1 \% \mathrm{OsO}_{4}, 0.1 \mathrm{M}$ cacodylate. The specimens were then routinely dehydrated in graded alcohols and propylene oxide and embedded in Spurr low-viscosity medium.

Thin sections $(50-70 \mathrm{~nm})$ were obtained with a diamond knife and collected on copper grids for morphologic and cytochemical evaluation of content. Specimens processed for vicinal glycol staining were collected on stainless-steel grids for sequential incubation in periodic acid-thiocarbohydrazide-silver proteinate (PA-TCH-SP) as described previously (Fittschen et al., 1983). Thin sections were counterstained with uranyl acetate and lead citrate, and examined with a Philips 300 electron microscope at an accelerating voltage of $60 \mathrm{kV}$.

Methanolic uranyl acetate and lead citrate stained marrow late heterophils (containing two or more nuclear lobes with condensed nuclear chromatin) were sequentially photographed ( $n=10$ micrographs) from each of the first three rabbits studied in FeD and control groups. For morphometric studies, the micrographs $(7 \times 9$ in format $)$ were evaluated with a graf/Pen sonic digitizer connected to a Hewlett-Packard 9825 A calculator. The outline of each cell and its nucleus were traced with a sonic pen and the $x$ and $y$ coordinates of successive points were transmitted to a calculator, thus allowing calculation of cytoplasmic and nuclear area (Bishop and Drummond, 1979). In the point counting mode, the number of primary and secondary granules were enumerated. Primary granules were identified by their content of variably extracted osmiophilic material and large size $(0.2-0.8 \mu \mathrm{m})$ and secondary granules by their homogeneous moderately dense content and generally smaller diameter $(0.1-0.5 \mu \mathrm{m})$ (Bainton and Farquhar, 1966; Wetzel et al., 1967a). The granule counts were expressed as numbers of granules per square micrometer of cytoplasm. Although only the first three rabbits in each group were evaluated statistically for granule number, qualitative assessment of heterophil granules using cytochemical and morphologic techniques were performed on samples from all rabbits.

\section{RESULTS}

\section{Hematologic Parameters}

At the initiation of experiments, control rabbits $(n=4)$ weighed $2.49 \pm 0.22 \mathrm{~kg}$ and those to be made iron-deficient $(n=5), 2.75 \pm 0.36 \mathrm{~kg}$ (mean \pm SD). Control and FeD rabbits were fed their designated diets for $30.0 \pm 15.0$ and $33.8 \pm$ 12.1 days, respectively. Expressed as a percentage of initial weight, control 
rabbits gained $9.5 \pm 12.5 \%$ during the experiments and $\mathrm{FeD}$ rabbits lost $3.5 \pm$ $6.7 \%$. Moderately severe iron deficiency was produced in the FeD animals, indicated by decreased hematocrit and serum iron concentration and by elevated serum total iron-binding capacity (Table I). FeD rabbits also exhibited a significantly decreased LAP score and significantly increased reticulocyte percentage (Table I) as previously described in iron-deficient rabbits (Celada et al., 1979).

\section{Electron Microscopy}

Morphology. Heterophils from bone marrow, peripheral blood, and peritoneal washes in FeD rabbits had similar or increased numbers of primary and secondary granules (Fig. 1, Table II) despite the observed decrease in alkaline phosphatase in FeD rabbits (Table I). Similarly, no significant difference in either cell or cytoplasmic area could be demonstrated (Table II). Primary granules in both animal groups varied from 0.2 to $0.8 \mu \mathrm{m}$ in diameter and contained variable amounts of osmiophilic material which cither diffuscly filled the granule or appeared more prominent in the granule rim. In contrast to primary granules, secondary granules were less dense in unstained specimens, lacked significant osmiophilia, and measured 0.1-0.5 $\mu \mathrm{m}$ in diameter in both control and FeD rabbits. Methanolic uranyl acetate and lead citrate moderately and homogeneously stained secondary granules (Fig. 1). Although some vacuolization was seen in heterophils from $\mathrm{FeD}$ rabbits, morphologic differences in secondary granules could not be demonstrated in the FeD and control rabbits. Mitochondria were infrequently observed in control and iron-deficient rabbits. No vesiculation or abnormal membranes were observed in mitochondria from iron-deficient animals when compared to controls.

Cytochemistry. PA-TCH-SP staining of vicinal glycols in secondary granules was similar in all $\mathrm{FeD}$ and control specimens (Fig. 2). Immature primary granules in promyelocytes and myelocytes stained moderately whereas staining appeared

much weaker in mature primary granules of late heterophils in $\mathrm{FeD}$ and control animals, although a tendency toward increased primary granule staining was observed in FeD animals. Alkaline phosphatase was markedly decreased or absent in FeD heterophils, whereas characteristic crescent staining of control heterophil secondary granules was observed (Fig. 3). Acid phosphatase stained immature primary granules in promyelocytes and myelocytes but appeared masked in the mature primary granules of segmented heterophils (Fig. 4). Tertiary granules varied from 0.1 to $0.2 \mu \mathrm{m}$ in diameter and demonstrated homogeneous acid phosphatase staining. Generally less than three acid phosphatase-positive tertiary granules were observed per cell profile. Peroxidase normally stained most primary granules (Fig. 5).

\section{Biochemical Data}

A decrease in alkaline phosphatase was consistently observed in FeD $(n=4)$ peritoneal wash heterophils $\left(0.061 \pm 0.016 \mu \mathrm{mole} / 10^{6} \mathrm{cells}\right)$ in contrast to simultaneously prepared $(n=2)$ and nonsimultaneous controls $(n=10)$, which had values of 0.420 and 0.155 , and $0.170 \pm 0.033 M / 10^{6}$ cells, respectively $(P<0.001$, Student's $t$ test). $\beta$-Glucuronidase, a primary granule marker, was present in similar quantities in FeD and control animals with values of $0.512 \pm 0.246$ and 0.656 $\pm 0.141 \mathrm{OD} / \mathrm{ml} / 10^{6}$ cells, respectively. 


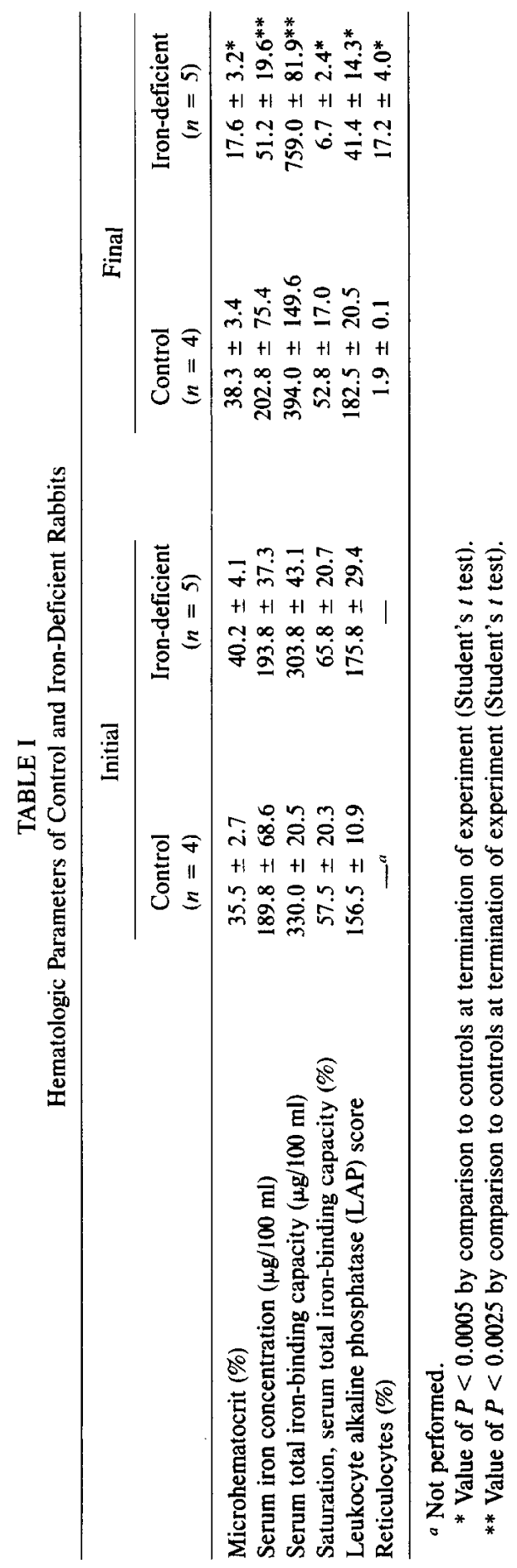



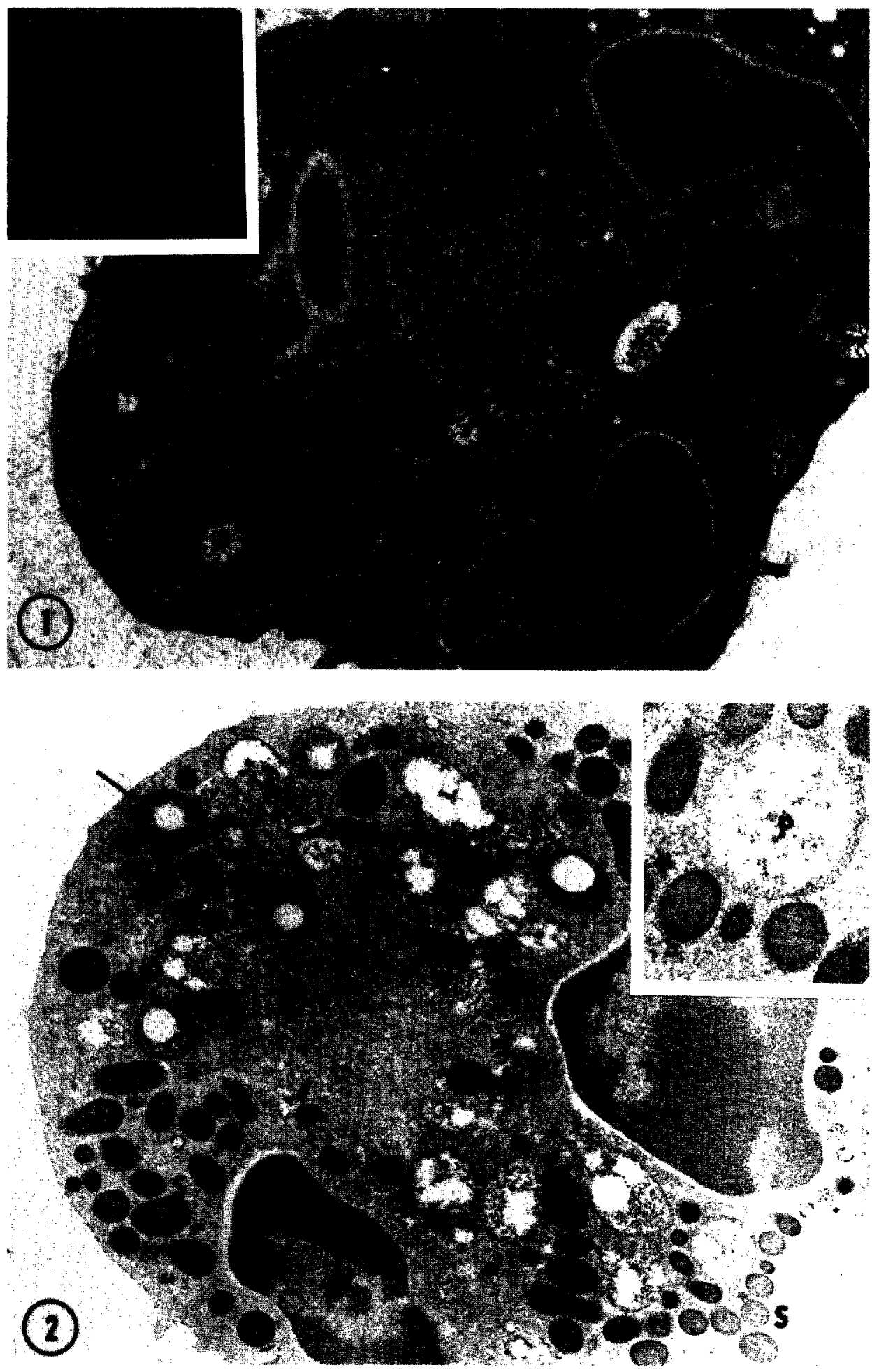

FIG. 1. Primary and secondary granules are abundant in this heterophil from an iron-deficient rabbit. Primary granules $(\mathrm{P})$ are larger and demonstrate increased peripheral staining, whereas secondary granules (S) arc smaller and stain homogeneously (enlarged in inset). Some primary granules appear extracted (arrows). Nuclei $(\mathrm{N})$. Bone marrow specimen. Thin section stained with methanolic uranyl acetate and lead citrate. $\times 20,000$; Inset $\times 50,000$ 
TABLE II

Heterophil Cytoplasmic Granules

\begin{tabular}{lcccc}
\hline & $\begin{array}{c}\text { Primary granules } \\
\text { per } 10 \mu \mathrm{m}^{2} \text { cytoplasm } \\
(\mathrm{Mean} \pm \mathrm{SD})\end{array}$ & $\begin{array}{c}\text { Secondary granules } \\
\text { per } 10 \mu \mathrm{m}^{2} \text { cytoplasm } \\
(\mathrm{Mean} \pm \mathrm{SD})\end{array}$ & $\begin{array}{c}\text { Cell profile } \\
\text { area in } \mu \mathrm{m}^{2} \\
(\mathrm{Mean} \pm \mathrm{SD})\end{array}$ & $\begin{array}{c}\text { Cytoplasmic } \\
\text { area in } \mu \mathrm{m}^{2} \\
(\mathrm{Mean} \pm \mathrm{SD})\end{array}$ \\
\hline $\begin{array}{l}\text { Iron-deficient rabbits } \\
\text { Rabbit } 1(n=10)\end{array}$ & $8.2 \pm 3.0$ & $22.8 \pm 4.9$ & $26.1 \pm 6.9$ & $19.5 \pm 5.8$ \\
Rabbit $2(n=10)$ & $8.4 \pm 1.8$ & $31.9 \pm 6.5$ & $25.1 \pm 3.8$ & $17.1 \pm 4.0$ \\
Rabbit $3(n=10)$ & $4.8 \pm 2.7$ & $27.7 \pm 6.2$ & $27.9 \pm 4.6$ & $20.0 \pm 4.5$ \\
Total $(n=30)$ & $7.2 \pm 3.0$ & $27.4 \pm 6.84^{*}$ & $26.4 \pm 5.2$ & $18.6 \pm 5.2$ \\
Control rabbits & & & & \\
Rabbit $1(n=10)$ & $6.4 \pm 2.7$ & $17.4 \pm 4.5$ & $31.0 \pm 7.8$ & $21.1 \pm 6.8$ \\
Rabbit $2(n=10)$ & $5.5 \pm 2.4$ & $21.0 \pm 7.0$ & $28.9 \pm 9.3$ & $20.2 \pm 5.7$ \\
Rabbit $3(n=10)$ & $5.5 \pm 2.5$ & $17.8 \pm 4.4$ & $28.6 \pm 5.0$ & $21.7 \pm 6.4$ \\
Total $(n=30)$ & $5.8 \pm 2.5$ & $18.7 \pm 5.5^{*}$ & $29.5 \pm 7.4$ & $21.0 \pm 6.1$ \\
\hline
\end{tabular}

a Data derived from 10 consecutive and random micrographs of heterophils from each rabbit marrow specimen with $n=3$ rabbits in FeD and $n=3$ in control groups. Each heterophil profile contained at least two nuclear profiles with predominantly condensed nuclear chromation.

* $P$ value $<0.001$ by Student's $t$ test.

\section{DISCUSSION}

The present study demonstrates that despite the acquired deficiency of secondary granule enzymes induced by iron deficiency, a decrease in granule number and size does not occur. The decrease in alkaline phosphatase consistently observed in these cells is similar to that previously reported for iron-deficient heterophils (Celada et al., 1979) and extends those results to the ultrastructural level. The decrease in enzyme activity cannot be attributed to a general decrease in lysosomes, but to a selective decrease in specific enzymes. In humans, neutrophil alkaline phosphatase has been localized in a vesicle fraction (Borgers et al., 1978; Wilson et al., 1981), rather than secondary granules as in rabbit heterophils (Bainton and Farquhar, 1968; Wetzel et al., 1967b), but its deficiency is frequently associated with abnormalities or numerical deficiencies of secondary granules (Parmley et al., 1980a; Strauss et al., 1974). The present study demonstrates that a deficiency of alkaline phosphatase is not necessarily associated with a decrease in number of secondary granules. The crescent distribution of alkaline phosphatase in normal control heterophil secondary granules is similar to that in previously reported studies (Bainton and Farquhar, 1968; Wetzel et al., 1967b). The marked decrease in ultrastructural staining of alkaline phosphatase in iron deficiency is consistent with light microscopic and biochemical documentation of decreased akaline phosphatase in these cells from FeD rabbits. This decrease in activity is present in bone marrow, peripheral blood, and tissue compartments.

Vicinal glycol content, assessed using Thiery's PA-TCH-SP method, does not appear altered in iron-deficient secondary granules in the present study. Secondary granules are known to have a large amount of glycoprotein (Noseworthy et al., 1975), which presumably represents the predominant staining with this

FIc. 2. PA-TCH-SP intensely stains vicinal glycol groups in secondary granules (S) of this irondeficient rabbit (enlarged in inset). Mature primary granules (P) stain weakly whereas stronger irregular staining is evident in immature primary granules (arrows), some of which appear extracted or vacuolated. The staining of FeD primary granules appears slightly increased when compared to control rabbits. Nuclei $(\mathrm{N})$. Bone marrow specimen. $\times 18,000$; inset $\times 45,000$. 

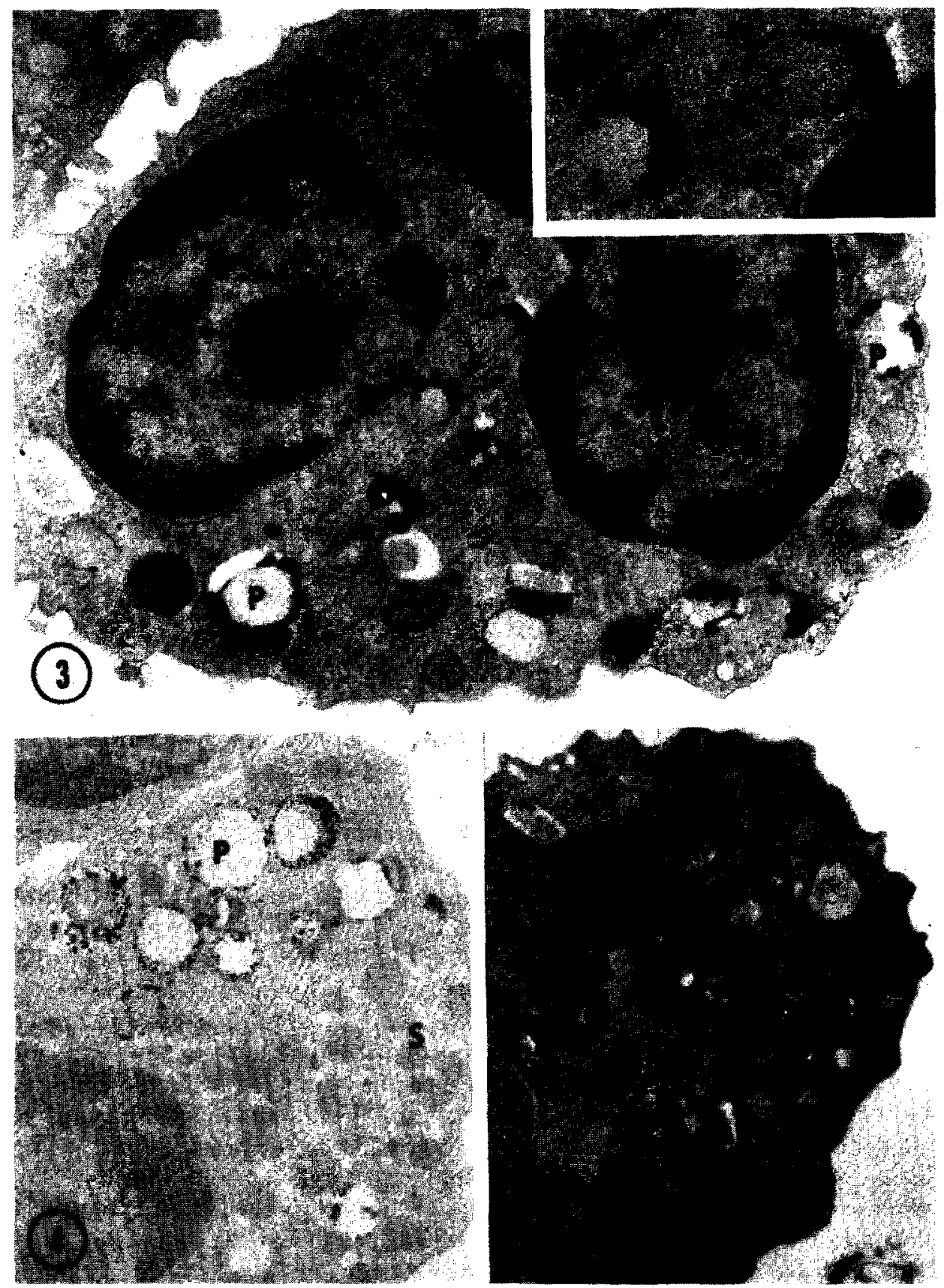

FIG. 3. This metamyelocyte from a control rabbit demonstrates typical, crescent distribution of alkaline phosphatase staining in several secondary granules ( $S$, enlarged in inset). Primary granules (P) lack staining. Staining was markedly decreased or absent in iron-deficient rabbits. Bone marrow specimen, not counterstained. $\times 20,000$; inset $\times 45,000$

FIG. 4. Acid phosphatase reactivity is present in a diffuse or rim pattern in primary granules (P) of a myelocyte from this iron-deficient rabbit (similar to control rabbits). Secondary granules (S) lack staining. Bone marrow specimen. Thin section not counterstained. $\times 15,000$.

FIG. 5. Primary granules ( $P$ ) from this iron-deficient rabbit demonstrate myeloperoxidase reactivity. Although some granules appear to be less reactive, similar variability was seen in control rabbits. Secondary granules (S) lack staining. Nucleus $(\mathrm{N})$. Bone marrow specimen. Thin section not counterstained. $\times 13,000$. 
method. Vicinal glycol staining does appear to be relatively specific for human neutrophil and rabbit heterophil secondary granules (Fittschen et al., 1983; Parmley et al., 1980b). The normal-to-increased quantities of positively stained granules further confirms morphologic observations in iron deficiency.

Primary granules of iron-deficient heterophils also do not appear to be decreased in number in comparison to control cells. This is consistent with the relatively normal amount of $\beta$-glucuronidase observed in these cells in this study and the presence of acid phosphatase and peroxidase observed cytochemically. Previous studies have suggested that some deficiency in heme-containing myeloperoxidase may be present (Mackler et al., 1984; Sinha and Swarup-Mitra, 1981). Our failure to document this with ultrastructural benzidine staining may be related to the increased sensitivity of the technique, which results in intense staining even when small amounts of heme are present. The present study demonstrates that if enzymatic deficiency is present in these primary granules, the deficiency is not expressed by a decrease in granule number.

The tendency of increased granules per unit area observed in iron-deficient animals may be comparable to an increase in the hepatocyte mitochondrial compartment (although largely due to an increase in organelle size) in iron-deficient animals despite a decrease in their cytochrome enzymes (Dallman and Goodman, 1971). The finding in heterophils conceivably could be a secondary phenomenon related to either marrow environment or hypercellular marrow activity. Alternatively, an increase in granules may represent a compensatory mechanism to increase granule number when granules are produced with deficient constituents.

Although decreases in granule number and size were not observed, some cytoplasmic vacuoles were observed. However, even this appeared relatively subtle. Previous ultrastructural and biochemical studies of iron-deficient hepatocytes have shown an increase in mitochondrial vesiculation and a decrease of cytochromes A and C (Dallman and Goodman, 1971). The paucity of mitochondria in control and iron-deficient heterophils and the relatively short life span of heterophils may account for the lack of a noticeable involvement of this organelle in heterophils.

\section{REFERENCES}

Bainton, D. F., and FARQUHAR, M. G. (1966). Origin of granules in polymorphonuclear leukocytes. Two types derived from opposite faces of the Golgi complex in developing granulocytes. J. Cell. Biol. 28, 277.

Bainton, D. F., and Farquhar, M. G. (1968). Differences in enzyme content of azurophil and specific granules of polymorphonuclear leukocytes. II. Cytochemistry and electron microscopy of bone marrow cells. J. Cell. Biol. 39, 299.

Barka, T., and Anderson, P. T. (1967). "Histochemistry: Theory, Practice, and Bibliography," p. 238. Harper \& Row, New York.

Bishop, S. P., and Drummond, J. L. (1979). Surface morphology and cell size measurement of isolated rat cardiac myocytes. J. Mol. Cell. Cardiol 11, 423.

Borgers, M., Thone, F., DE Cree, J., and DE COCK, W. (1978). Alkaline phosphatase activity in human polymorphonuclear leukocytes. Histochem. J. 10, 31 .

Bretz, U., and BAGgiolin, M. (1974). Biochemical and morphological characterization of azurophil and specific granules of human neutrophilic polymorphonuclear leukocytes. J. Cell. Biol. 63, 251. ,

Celada, A., Herreros, V., Pugin, P., and Rudolf, H. (1979). Reduced leukocyte alkaline phosphatase activity and decreased NBT reduction test in induced iron deficiency anaemia in rabbits. Brit. $J$. Haematol. 43, 457.

Chandra, R. K. (1973). Reduced bactericidal capacity of polymorphs in iron deficiency. Arch. Dis. Child. 48, 864.

Dallman, P. R., and Goodman, J. R. (1971). The effects of iron deficiency on the hepatocyte: A biochemical and ultrastructural study. J. Cell. Biol. 48, 79. 
DE VET, B. J., and TEN HOOPEN, C. H. (1978). Lactoferrin in human neutrophilic polymorphonuclear leukocytes in relation to iron metabolism. A'cta Med. Scand. 203, 197.

DUNN, W. B., HARDIN, J. H., and SPICER, S. S. (1968). Ultrastructural localization of myeloperoxidase in human neutrophil and rabbit heterophil and esoinophil leukocytes. Blood 32, 935.

Fittschen, C., Parmley, R. T. Austin, R. L.. and Crist, W. M. (1983). Vicinal glycol-staining identifies secondary granules in human normal and Chediak-Higashi neutrophils. Anat. Rec. 205, 301.

Graham, R. C., JR., and KarNovSKY, M. J. (1966). The early stages of absorption of injected horseradish peroxidase in the proximal tubules of mouse kidney: Ultrastructural cytochemistry by a new technique. J. Histochem. Cytochem. 14, 291.

Hunt, C. E. and HarRington, D. D. (1974). Nutrition and nutritional diseases of the rabbit. In "The Biology of the Laboratory Rabbit" (S. H. Weisbroth, R. E. Flatt, and A. L. Kraus, eds), Chapt. 16, p. 403. Academic Press, New York.

Mackler, B., Person, R., Ochs, H., and Finch, C. A. (1984). Iron deficiency in the rat: Effects on neutrophil activation and metabolism. Pediatr. Res. 18, 549.

Mayahara, H., Hikano, H. M., Saito, T., and Ogawa, K. (1967). The new lead citrate method for the ultracytochemical demonstration of activity of nonspecific alkaline phosphatase (orthophosphoric monoester phosphohydrolase). Histochemie 11, 88.

MicheLl, R. H., KARNOVSKY, M. J., and KaRNOVSKY, M. L. (1970). The distributions of some granuleassociate enzymes in guinea-pig polymorphonuclear leukocytes. Biochem. J. 116, 207.

Noseworthy, J., Smith, G. H., Himmel hock, S. R., and Evans, W. H. (1975). Protein and glycoprotein electrophoretic patterns of enriched fractions of primary and secondary granules from guinea pig polymorphonuclear leukocytes. J. Cell. Biol. 65, 577.

Okun, D. B., and Tanaka, K. R. (1978). Leukocyte alkaline phosphatase. Amer. J. Hematol. 4, 293.

Parmley, R. T. Crist, W. M., Ragad, A. H., Boxer, L. A., Malluit, A., Lui, V. K. and Dardy, C. P. (1980a). Congenital dysgranulopoietic neutropenia: Clinical, serologic, ultrastructural, and in vitro proliferative characteristics. Blood 56, 465.

Parmley, R. T., Eguchi, M., Spicer, S. S., Alvarez, C. J., and Austin, R. L. (1980b). Ultrastructural cytochemistry and radioautography of complex carbohydrates in heterophil granulocytes from rabbit bone marrow. J. Histochem. Cytochem. 28, 1067.

PRASAD, J. S. (1979). Leukocyte function in iron-deficiency anemia. Amer. J. Clin. Nutr. 32, 550.

Sinha, A. K., and Swarup-Mitra, S. (1981). Myeloperoxidase activity in polymorphonuclear neutrophils in nutritional anaemia. Trans. R. Soc. Trop. Med. Hyg. 75, 758 (Letter).

Straisss, R. G., Bovf, K. E., Jonf., J. F., Mauffr, A. M., and Fiti Giniti, V. A. (1974). An anomaly of neutrophil morphology with impaired function. N. Engl. J. Med. 290, 478.

Van Heerden, C., Oosthuizen, R., Van Wyk, H., Prinsloo, P., and Anderson, R. (1981). Evaluation of neutrophil and lymphocyte function in subjects with iron deficiency. S. Afr. Med. J. 59, 111.

Wetzel, B. K., Horn, R. G., and Sicer, S. S. (1967a). Fine structural studies on the development of heterophil, eosinophil, and basophil granulocytes in rabbits. Lab. Invest. 16, 349.

Wetzel, B. K.. Spicer. S. S.. and Horn, R. G. (1967b). Fine structural localization of acid and alkaline phosphatases in cells of rabbit blood and bone marrow. J. Histochem. Cytochem. 15, 311.

Wilson, P. D., Rustin, G. J., and Peters, T. J. (1981). The ultrastructural localization of human neutrophil alkaline phosphatase in normal individuals during pregnancy and in patients with chronic granulocytic leukaemia. Histochem. J. 13, 31.

Yetgin, S., Altay, C., Cilvic, G., and Laleli, Y. (1979). Myeloperoxidase activity and bactericidal function of PMN in iron deficiency. Acta Haematol. 61, 10. 